Indexed by

\title{
SUPERVISOR'S CAPABILITY AND APTITUDE TO SUPERVISE HEALTH AND SAFETY (H\&S) INDUCTION TRAINING TO SITE WORKFORCES: A CASE STUDY OF THE CONSTRUCTION INDUSTRY OF PAKISTAN
}
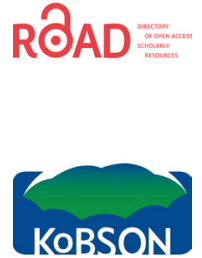

\section{Hafiz Daniyal Khalid}

National University of Modern Languages, Department of Management Sciences, Islamabad, Pakistan

\section{Bilal Aslam}

Riphah International University, Department of Data Science, Islamabad, Pakistan

\author{
Umer Khalil \\ COMSATS University, \\ Department of Civil \\ Engineering, Islamabad, \\ Pakistan
}

Key words: construction industry, Health and Safety (H\&S), H\&S induction training, Pakistan, supervisors

doi:10.5937/jaes0-31072

Cite article:

Khalid Daniyal H., Aslam B., Khalil U. (2021) SUPERVISOR'S CAPABILITY AND APTITUDE TOSUPERVISE HEALTH AND SAFETY (H\&S) INDUCTION TRAINING TO SITE WORKFORCES: A CASE STUDY OF THE CONSTRUCTION INDUSTRY OF PAKISTAN, Journal of Applied Engineering Science, 19(4), 962 - 971, DOI:10.5937/ jaes0-31072

Online aceess of full paper is available at: www.engineeringscience.rs/browse-issues 


\title{
SUPERVISOR'S CAPABILITY AND APTITUDE TO SUPERVISE HEALTH AND SAFETY (H\&S) INDUCTION TRAINING TO SITE WORKFORCES: A CASE STUDY OF THE CONSTRUCTION INDUSTRY OF PAKISTAN
}

\author{
Hafiz Daniyal Khalid ${ }^{1}$, Bilal Aslam ${ }^{2 *}$, Umer Khalil ${ }^{3}$ \\ ${ }^{1}$ National University of Modern Languages, Department of Management Sciences, Islamabad, Pakistan \\ ${ }^{2}$ Riphah International University, Department of Data Science, Islamabad, Pakistan \\ ${ }^{3}$ COMSATS University, Department of Civil Engineering, Islamabad, Pakistan
}

Health and Safety (H\&S) is a professional approach to substitute harmless and vigorous work conditions for any industry. The construction industry is of utmost importance because it is associated with elevated accident rates compared to the other sectors. To some extent, cultural progression is also reliant on communication among all the groups inside a corporation. Effective communication happens in a construction corporation, among upper management and the employees arbitrated by the supervisors. Therefore, if the construction supervisor's capabilities are ignored, the plans to progress the satisfactory H\&S culture may be unsuccessful. The aptitude for conducting H\&S induction training to employees is one of the construction supervisor's abilities, and in developing countries, the supervisor's capabilities are ignored. Moreover, the organization's eagerness on H\&S, which corresponds to the induction training, is relatively less. The current research reports an examination to analyze how the supervisors possess $H \& S$ capabilities and skills to oversee site H\&S induction training to workforces successfully. For the analysis, Pakistan's construction industry was targeted, and numerous construction firms were contacted in this regard. The data for the intended objective was accumulated through talks and surveys with site supervisors in construction companies of various extents from all over Pakistan. The outcomes exposed insufficient training, an absence of management dedication, and an inadequate familiarity or usage of visual/audio communication assistance by construction companies in Pakistan. Thus, it is suggested that there is a need for the supervisors to understand the use of multilingual skills and current technologies to assist valuable site H\&S induction training that can progress a path towards an optimistic H\&S culture.

Key words: construction industry, Health and Safety (H\&S), H\&S induction training, Pakistan, supervisors

\section{INTRODUCTION}

In the economy of any country, either it is developed or developing, a vital role is played by the construction industry. It is witnessed that the economic development of a country is influenced a lot by the construction industry (Le, Shan et al. 2014). The construction industry comprises equipment, workers, raw materials, and energy. The construction industry, globally, comes up with an inconsistent number of mishaps. The construction business is counted as one of the utmost hazardous businesses for workers (Imriyas, Pheng et al. 2007, Amiri, Ardeshir et al. 2017). All around the sphere, the health of the employees, equipment, assets, and ultimately the output and financial system of the state has been affected by the accidents at construction sites. The upsurge in the calamity incidents arises because of the variation in humanoid conduct and site circumstances (Abdelhamid and Everett 2000). The growing risks for workforces worldwide are also highlighted by the International Labor Organization (ILO), specifically in construction, where the proportion of deadly mishaps might be 10 otherwise even 20 times more significant compared to the typical (ILO 2010).
The calamities that went unreported could be excessive because more than $90 \%$ of construction site workforces are rural nomadic workers with no elementary schooling (Chan, Wong et al. 2017). Furthermore, the outcomes of an investigation led by the Health and Safety Executive (HSE) in the United Kingdom (UK) have revealed that the informing extent of mishaps in the construction industry is merely around 55\% (HSE 2010). The construction industry is one of the ultimate of all industries with regard to lost workday cases, with above $60 \%$ of the instances stemming because of musculoskeletal grievances (ILO 2005). According to Goetsch (2012), the foremost reasons for site mishaps are slips, transportation, and machinery accidents, falls from heights, besides electrocution. As usual on construction sites, striding or hitting against minor items, strains and sprains are also identified by Fewings (2010). Workers, every single day of their lives at work sites, face these risks. Workforces are indispensable to any corporation. Construction site workforces are the 'human capital' of any construction organization, as stated by Lutchman, Maharaj et al. (2012). For efficient execution of their regular maneuvers, the workforces need development and training. Conferring 
to Goetsch (2012), H\&S training of workforces not only enables the workers to do their works safely, but it also establishes consciousness of the presence of workplace hazards. Though, in emerging nations such as Pakistan, the contractors are not as much devoted to workforce H\&S in contrast to established countries as suggesting the available research findings.

The construction industry in Pakistan accounts for $7.31 \%$ of the workforce, according to the Pakistan Bureau of Statistics as of 2016 (Khan, Ali et al. 2019). In an emerging country like Pakistan, insecure situations in the work environment cause time delay, low productivity, and health problems (Farooqui and Ahmed 2008). The safety guidelines are mere a "formalism" deprived of any practical execution in the maximum of Pakistan's construction firms. The very high calamity incidents on safety sites in Pakistan are due to this utmost reason. Though a nation must guarantee an extraordinary national-level association that should handle the safety-associated complications in any industry, as Choudhry, Fang et al. (2008) recommended. In Pakistan, the protocols of occupational H\&S are substandard. Yet, a few businesses do not have rules or guidelines for safety (Memon, Soomro et al. 2017). In Pakistan, the deficiency of human progress in capacities, such as H\&S training of workforces and supervisors, is why construction firms do not obey H\&S protocols. The absence of administrative funds and upper administration obligation in employees $\mathrm{H} \& \mathrm{~S}$ among signing corporations in the evolving states cause considerable encounters to site H\&S management as observed by the reports of HSE (2010). Various investigations steered in the emerging countries have revealed that the nonexistence of executive means and inadequate H\&S training of workforces influences deprived site H\&S management.

In all the fields influencing construction supervisors' work environment, they need to be capable, mainly with the construction site's exclusive and multifaceted features (Musonda, Pretorius et al. 2012). The intricacy is added by the widespread utilization of amateurish and rural nomadic workforce (Okorie and Smallwood 2012). In Southern Florida, the investigation led by Vazquez and Stalnaker (2004) among Hispanic refugee construction site workers resolved that these sorts of site workforces cause a severe challenge to the efficient demeanor of site H\&S training. Moreover, subsequent are some of the exclusive characteristics of a construction site that interpose to its intricacy. An enormous number of subcontractors on site as one of the exceptionalities of the construction business is noted by Musonda, Pretorius et al. (2012).

In contrast, impermanent work sites where diverse companies hire workers; however, work along with all and sundry was observed by Kheni (2008). The momentary workforce characterizes the construction work (Spangenberg 2009), and the maximum of the construction site workers do not have employment established prerequisite (Okorie and Smallwood 2012). Besides, Chan, Javed et al. (2016) assert that the bulk of construction site workforces have meager verbal English thoughtful- ness, which influences undesirably on their consciousness. Furthermore, to the intricacy of the industry, supervisors are deficient in the competencies, skills, and abilities to administrate safety induction training to the site workforces (Hughes and Ferrett 2012). All these aspects collectively could influence destructively to efficient site H\&S management.

H\&S induction training is provided to the new trainees, employees, and subcontractor's workforce to acquaint them with the site conditions of an organization's H\&S, rule, and work excellence (Naoum 2011). Conducting consistent site H\&S guidance, for instance, toolbox talks and induction to workers, not solely impart abilities to the workers to take care of themselves; however, it also endowed them to carefully do their work, as asserted by Hughes and Ferrett (2012). Site H\&S induction training of employees is being stressed significantly as a vehicle that energies H\&S culture by Fewings (2010). The training of the workforce has been related to capability. Commitment, competency, leadership, communication, involvement, and procedures are identified as crucial aspects of H\&S culture by Musonda and Haupt (2011). Aptitude is indispensable to cultural growth. Conferring to Lingard and Rowlinson (2005), altering the perspectivity behavior of construction site workforces will be problematic if deprived of devotion in site H\&S training. The prominence of H\&S induction training to the site workers has been accepted as the primary stage to teach workers on prevailing threats, the organization's H\&S rule, and probable eminence of the job. Hence, the person must be competent enough to manage H\&S induction training to the site workforce.

There are many existing H\&S-related studies, but researchers of developed countries have mainly carried them out. In developing countries like Pakistan, investigations conferring H\&S induction by site supervisors persist in being insufficient regardless of the magnitude of H\&S induction to progressing decent H\&S values and the profoundness of those who lead it, precisely their aptitude. Thus, the setback is that even though the administrations have well-envisioned policies and programs to foster good H\&S cultures, it is dubious that accomplishment might be comprehended if supervisor H\&S capabilities and aptitude to interconnect efficiently to workforces are not spotlighted. This research aims to offer replies to the specified queries on the significance of supervisor capability and skill to perform H\&S induction and, in so doing, interconnect an administration's social standards. The present research aims to identify the extent to which the site supervisors have the capacity and skillset for $\mathrm{H} \& S$, the competency to conduct H\&S training and workshops, and identify influential factors on H\&S training. This study on supervisor's capability to supervise H\&S induction training is vital because it highlights the lack of interest of organizations in the practice of H\&S induction by site supervisors due to the supervisor's inabilities. UItimately it can act as an indicator for the authorities to take appropriate actions concerning this problem. 


\section{LITERATURE REVIEW}

\section{Site H\&S induction training and dedication of the management}

The H\&S behavior of supervisors and workforces on sites is determined by the dedication of higher administration to organizational H\&S. The acceptance of site H\&S training to workforces, formulation of organization $\mathrm{H} \& S$ strategy, and distribution of funds for H\&S training are the responsibilities of the senior management (Spangenberg 2009). The supervisor's H\&S capability, besides its behavior regarding site H\&S induction training, is determined by the higher administration's devotion to H\&S, as asserted by Hinze (2006). In site H\&S management, a central role is played by senior management regardless of the size of the company. H\&S induction training is an obligation, and the Regulations necessitate that companies provide employees with mandatory training regarding the materials and working situation. Site H\&S training arouses consciousness among site workforce and construction professionals in a similar way, as asserted by (Lingard and Rowlinson 2005). It is recognized that maximum of the site mishaps befalls as workforces and supervisors are ignorant of risks that subsist in a specific work progression and particular parts of the site (Goetsch 2012). Consequently, in Pakistan, for the H\&S induction training to the site workforce, management obligation as adequate economic provision is imperative for supportable workplace H\&S culture.

\section{H\&S induction training and construction site supervisor}

In industrial mishap preclusion, a supervisor is a key man, as shown by the research over the years. As a frontrunner of a crew, the supervisor is entailed to be capable in all fields of H\&S supervision to empower him in leading his supervisory responsibility as a workforce's educator and mentor. Investigators have specified that inadequate site supervision is often responsible for a poor H\&S record (Hughes and Ferrett 2012, Lutchman, Maharaj et al. 2012). In acknowledging the association's status among a secure site H\&S implementation and supervisor's H\&S responsibilities, both the Decrees and Public Regulation enforces an obligation of the overhaul on the company to deliver and keep a capable site supervisor (Choudhry, Fang et al. 2008). This compulsion comprises the responsibility to offer (1) capable supervisor to safeguard $\mathrm{H} \& S$ at work of all individuals, (2) satisfactory equipment and plant, (3) harmless work, and (4) a harmless working arrangement.

A correspondingly significant H\&S supervisory responsibility on site is offered by construction site supervisors worldwide (Musonda, Pretorius et al. 2012). Training of workforces, new employees, disciplining of workforces, management, and inspiration of workforces are handled by the supervisor as conferred by Lutchman, Maharaj et al. (2012). All these significant responsibilities performed by supervisors entail competency and skills. If the construction corporations want to enhance site $H \& S$ execution, they must accord supervisors H\&S training a vital status as affirmed by Hughes and Ferrett (2012). Debatably, training and educating supervisors regarding exclusive features of their H\&S obligations offer them the essential aptitudes, which will better their competencies in steering $\mathrm{H} \& \mathrm{~S}$ induction training to the site workforce.

\section{Supervisor's H\&S capability}

There is an excellent relationship between efficient management of H\&S induction training at the site and the supervisor's H\&S capability. Site supervisors, because of their status as a coordinator to the workforce, educator, and mentor, mandate that they have pertinent $\mathrm{H} \& \mathrm{~S}$ abilities and proficiencies (Brauer). Supervisors are at elevated hazard to themselves and workforces due to the absence of the H\&S essential skills and competencies (Goetsch 2012). Hence, for efficient management of H\&S induction training to site workforces, supervisors must have crucial H\&S abilities. Conferring to Hinze (2006), not only H\&S induction training to site workforces is negatively impacted; however, site H\&S performance correspondingly due to the absence of competencies and skills among site supervisors. During site H\&S induction training, the supervisors will be able to transmit their skills to the workforce if and only if they have grasped the mandatory H\&S training. The skills learned by the instructor are proportional to the superiority of $\mathrm{H} \& \mathrm{~S}$ induction training of site workforces, as mentioned by Hughes and Ferrett (2012). Therefore, as supervisors' training has a beneficial influence on the workforce and organization, their H\&S training should be seriously regarded as an essential aspect by the top management. Hinze (2006) contends that an elevated rate of site incidents and mishaps can be experienced by an administration that disregards the supervisor's H\&S training and education.

\section{Current H\&S teaching technologies and supervisors}

In developing countries, the bulk of the construction site workforces are unskilled rural nomad workers (Okorie and Smallwood 2012). These sorts of site workforces are unable to speak and comprehend verbal English. Consequently, in steering site H\&S induction training, the usage of present technologies, for instance, visual aids and translators, are becoming more and more imperative. Bust, Gibb et al. (2008) proclaim that among the workforce of varied cultures, the conduction site H\&S induction training, which uses translators, has attested to be efficient.

Conversely, in most evolving nations like Pakistan, these contemporary H\&S technologies are deficient, and where they subsist, supervisors are not competent and skillful enough to maneuver them (Lutchman, Maharaj et al. 2012). In the emerging states, lack of essential abilities among site supervisors in functioning the current technologies is a factor for deprived site H\&S execution. Hughes and Ferrett (2012) assert that in the growing states, the 
construction corporations must acknowledge the significance of these recent technologies by getting them and instructing supervisors on how to use them. On a construction site comprising nomadic Hispanic workers where visual and translator equipment were utilized for H\&S induction training, common accidents were recorded as discovered by Vazquez and Stalnaker (2004). Unfortunately, in Pakistan, the transcribers to their associated colleagues are the construction site workforce. A grave contest to overall site H\&S supervision conferring to Vazquez and Stalnaker (2004) is directing H\&S induction training at the construction site in English to those workforces who do not speak English as their home language.

\section{Workforce H\&S behavior as a result of site H\&S induction training}

For an ideal H\&S culture, H\&S induction training to construction site workforces is an unconditional obligation. Not only the consistent handling of H\&S induction training to site workforces provokes devotion to their work, but it also establishes consciousness of prevailing site threats. As the site H\&S induction training acquaints the fresh workforces to company H\&S strategy, risks, and hazards characteristic to the project site; therefore, it holds importance. According to Hinze (2006), as accidents are waiting to happen, the H\&S induction training to site workers, mainly to new workforces, is of utmost importance. Spangenberg (2009), in a comparable way, affirms that harmless work as an exercise not merely endorses a company's business image but also reimburse in terms of economic advantage. Such sites where consistent H\&S induction training to site workforces is managed by supervisors as expressed by numerous research investigations that these sites have minimal calamities rates.

\section{Complications to conduct H\&S induction training}

Related to factory-based manufacturing, the construction site pursuits are exclusive, and it becomes more complex due to the company of subcontractors and temporary workforces (Sunindijo and Zou 2012). Besides the fleeting workforce, construction sites mainly comprise rural nomad workers who point to the metropolises once they are done with reaping their harvests (Okorie and Smallwood 2012). Another fact that makes efficient H\&S induction training a severe problem is that these site workforces have inadequate schooling and meager English thoughtfulness.

Observing breaks that subsist among supervisors (Vazquez and Stalnaker 2004), Okorie and Smallwood (2012) indicated that among the complications to a successful site induction training one is the absence of language skills, capability in linguistic understanding by supervisors through H\&S induction training. The following aspects are also recognized as hindrances to the efficient administration of site H\&S induction training by Lutchman, Maharaj et al. (2012) in the construction industry: (1) subcontractor's workforce (2) inadequate H\&S training (3) unskilled workforce (4) poor H\&S culture (5) unintentional work actions and (6) deficiency of resources for H\&S.
Concluding from the preceding mentioned impediments to efficient site H\&S induction training, it can be claimed that supervisors ought to be capable, have must the necessary H\&S abilities for efficient H\&S induction training to site workforces. Furthermore, the administration is importuned to devote to supervisors H\&S training to make them good mentors, guides, persuaders, and directors to employees.

\section{RESEARCH METHODOLOGY}

A mixed research method strategy was implemented to accomplish the goal and purposes of this investigation. The two extremes of the data continuum are the postulation fundamental to a mixed method to research (Flick 2014). By using qualitative and quantitative approaches correspondingly, the research problems can be understood better (Leedy and Ormrod 2010). On backing the implementation of mixed methods in exploration, Flick (2014) contends that the essential aim of a mixed method is to 'take on an investigation dilemma with a compilation of approaches with no interrelating limitation, additionally to their matching potencies.' The present investigation encompasses human behavior, and consequently, the mixed method was deliberated to be suitable. The qualitative technique involved steering talks. The interviewees were selected from site supervisors of the contacted construction firms (information about these construction firms is confidential as per the agreement). Firstly, the familiarity of the field; Secondly, must have been employed on a construction site in Pakistan; and Thirdly must have accomplished a minimum of 5 years of supervisory knowledge are the few conditions that were considered for interviewee selection.

Interaction with possible respondents presided with site supervisors from the small, medium, and large construction companies. There are different types of construction companies operating in Pakistan working on various infrastructure projects. A significant portion of these construction companies works on the local residential construction and mega commercial projects. In contrast, a few of the prominent national companies deal with the government infrastructure projects like the construction of highways, bridges, dams, etc. We choose the major companies working on key projects in the metropolises of Pakistan for the survey. Eleven construction corporations from all over Pakistan were communicated to partake in the investigation. They included two small, six medium, and three large-sized construction firms. The companies were sorted into these three categories (i.e., small, medium, large) based on their workforce potential. The firms with about 50 workers were termed as small, and the ones with about 150 workers were classed as medium-sized firms. The firms having more than 150 workers were categorized as large-sized firms.

The interviews were steered with twenty-four supervisors from these eleven different firms that took part in the research. The primary objective of these interviews was to have access to real-time and precise information. 
The quality of available information is the strength of the qualitative data collection rather than the sample's statistical strength. If the number of participants is less than 14 , still, it is possible to conduct phenomenological research (Flick 2014). The questionnaire for the interview was prepared in advance to control the debates. To acquire perceptiveness relative to the known problems, the interface between two or more people is called an interview (Leedy and Ormrod 2010, Flick 2014). Literature analysis on construction H\&S management exercises is the main source of the interview queries (Lingard and Rowlinson 2005, Goetsch 2012, Lutchman, Maharaj et al. 2012).

Furthermore, compared to supervising H\&S induction training to site workers, the queries permitted partaking supervisors to deliberate their abilities and competencies. With the respondents' erstwhile consent, the deliberations with each respondent were written down and were audio-recorded. Moreover, approval from the ethics committees of various companies was also acquired to record and publish the obtained data. The researchers listened to the recorded thoughts and propositions numerous times and afterward were written down by them. The written versions of the results were referred to the interviewees/participants who undeniably guaranteed that exact forms of the deliberations were gained. This assertion was done to enhance the validity of the results. The interview strategy of data gathering assisted the research. This strategy not only aided the researchers to have a finely signified sample lacking partiality, but it also increased the legitimacy and trustworthiness of the collected data.

A circulation of questionnaires to supervisors working in eleven construction firms within Pakistan was implicated in the quantitative data collection process. The distributed questionnaire was composed of three segments. There were 15 questions in the questionnaire where the majority of the questions were close-ended questions. In comparison, a few of the questions related to the experience and $\mathrm{H} \& \mathrm{~S}$ training required a brief reply from the participants. The demographic information was covered in the first portion. In the first segment, 'yes' and 'no' sort of replies was requested. The site H\&S induction and the practice of H\&S was included in the other sections. A five-point Likert scale was required to be rated by the respondents based on their responses. As personal interviews can influence the participants' responses because of the interviewer's attitude, this problem was solved by asking the participants the same questions as the questionnaire and offering them the same options as the questionnaire to choose from.

To the leading personnel working on different construction sites, overall, 150 questionnaires were disseminated. Though, only 106 questionnaires were adequately fulfilled, rendering a feedback rate of approximately $71 \%$. For the dissemination of the questionnaire, the face-toface way was preferred to avoid glitches of low feedback rate as time pressure being the cause for non-fulfillment of questionnaires is quoted by several site supervisors. Moreover, the face-to-face method enables the investi- gators to elucidate any query that the interviewee did not understand.

\section{RESULTS}

All the respondents who participated in this survey have a strong profile that should be enough to conclude that all respondents were qualified, experienced, and mature. Thus their responses can be relied on. $34 \%$ of the respondents have relevant construction-related local diplomas, while $42 \%$ of the participants have Higher Secondary School education, and $24 \%$ of the respondents have a Secondary School Certificate. $42 \%$ of the participants have worked in the construction industry for more than 10 years, $27 \%$ of the participants have more than 5 but less than 10 years of experience, while $31 \%$ of the participants have 2-5 years of work experience in the construction industry. Demographically, $56 \%$ of the respondents have ages between 35 years to 50 years, while $44 \%$ have ages between 25 years to 35 years.

\section{Supervisor H\&S capability}

The responses to the survey's primary question that have the supervisors conducted the H\&S training are tabularized in Table 1 . The results demonstrate that $34.9 \%$ of the interviewees had appeared in a supervisory $\mathrm{H} \& \mathrm{~S}$ training program, $54.7 \%$ had not, whereas $10.4 \%$ were not sure. A query was presented to supervisors during the talks to uncover whether the supervisors had appeared in any supervisory H\&S training before or not. The subsequent query was raised:

Q: - Have you appeared in any supervisory H\&S training program being a site supervisor?

Positive feedback in the form of 'yes' was witnessed by all the interviewees from big construction corporations.

Furthermore, it was also witnessed during the interview that some of the interviewees from big construction firms also have acquired training on management of volatile materials and the usage of personal protective equipment (PPE) besides the H\&S training of supervisors.

Conversely, compared to their counterparts, big firms' observations from the small-sized construction firms were dissimilar. The responses of respondents from small and medium-sized construction corporations are summarized subsequently. The overall response was that we have never appeared in any H\&S training programs. The administration/possessor of the construction firms where we are employed considers H\&S training a waste of funds.

It can be comprehended from the results that training mainly took place in more prominent corporations than smaller corporations. As evident from the quantitative investigation, less than $35 \%$ had gone through the H\&S training at the industry level. In Pakistan, the training of supervisors and the level of H\&S education appeared to reveal the extent of capability among the construction supervisors. 
Table 1: Rate of supervisory H\&S training conducted by supervisors

\begin{tabular}{|c|c|c|}
\hline & Frequency & Percent \\
\hline Yes & 37 & $34.9 \%$ \\
\hline No & 58 & $54.7 \%$ \\
\hline Not Sure & 11 & $10.4 \%$ \\
\hline Total & 106 & $100.0 \%$ \\
\hline
\end{tabular}

\section{Usage of audio/visual aids and translator equipment}

For H\&S communication, the usage of audio/visual assistance was also examined. The answers of the interviewees on whether they were able to operate or were aware of an audio/visual and translator apparatus were noted and are tabulated in Table 2. About $24.5 \%$ of the interviewees were mindful of and were capable to efficiently run visual/audio and translator apparatus as uttered by the results. On the contrary, $65.1 \%$ specified that they could not run the equipment efficiently, whereas $10.4 \%$ stated that they were not sure if they could operate the equipment or not because they were not aware of it. The subsequent query on the usage of technology to efficiently manage inductions was presented to supervisors:

Q: - Can you operate visual (audio) or translation equipment? Yes, I can efficiently manage audio (visual) and translation equipment, said one of the interviewees from a big construction corporation. He stated that I have appeared in programs on how to operate/use this equipment and have appeared in a language interpreting course.

On the other hand, the replies from smaller construction firms were not startling. Practically each of them made very similar observations. They mentioned that audio (visual) and translation equipment are not even present there. The organization/management considers these modern technologies to be very pricey, and none of them has ever appeared in any language training program.

A supervisor from a small-sized firm vigorously specified that: All the workforces are translators to their colleagues. Owing to the financial constraints, the company where I am employed cannot buy/acquire any of these teaching aids now.

From both the interviews and questionnaire, the findings indicate that technology usage is inadequate, specifically in smaller companies. The efficient conduction of site induction and communication to workforces by the supervisors may be hampered due to this limited use of technology.

Table 2: Rate of the effective operation of visual (audio) or translation equipment

\begin{tabular}{|c|c|c|}
\hline & Frequency & Percent \\
\hline Yes & 26 & $24.5 \%$ \\
\hline No & 69 & $65.1 \%$ \\
\hline Not Sure & 11 & $10.4 \%$ \\
\hline Total & 106 & $100.0 \%$ \\
\hline
\end{tabular}

\section{Accountable factors for supervisor' H\&S induction training abilities}

For efficient handling of site H\&S induction training, the impact of different factors on the supervisor's H\&S capabilities and aptitude has been rated by the respondents regarding the extent of the effect. The results of these ratings are exhibited in Table 3 . The replies for an individual score on a measure of 1 (minor) to 5 (major) in terms of percentage is shown in Table 3. The Mean Scores (MS) of all the eight categorized aspects exceed the midpoint of 3.00 , as can be perceived from the table. The numerical results to establish a ranking in Table 3 are very close, as all these factors were considerably related to H\&S and contribute to the primary cause. The main purpose of forming the hierarchy is to highlight the priority factors that contribute to the primary problem so that they can be addressed on the earliest basis by the management.

The mean MS of 3.77 specifies that the interviewees regarded the classified assertions as influencing the supervisor's capability and absence of aptitudes for efficient site H\&S induction training. The outcomes determine that the respondents seem to lack management devotion on worker's H\&S, the nonexistence of multilingual skills, and low educational level to be foremost influencing aspects to supervisor incapability to manage H\&S induction. All the former mentioned factors were classified as uppermost on the list. The interviews steered with supervisors also validated the survey questionnaire fallouts and literature. The succeeding comments were uttered by one of the interviewees:

The higher administration determines the company's $\mathrm{H} \& \mathrm{~S}$ regulations and operations. They consent to operate H\&S training and formulate the company's H\&S strategy. Regardless of the size of the company, it is the higher management devotion to H\&S that regulates supervisor's H\&S skills and capability, which, as a result, outlines their capacity and skills for an efficient handling of site H\&S induction training to site workforces. Bearing in mind the exclusive nature of the construction business and its complicated processes, the supervisors were presented with the following question:

Q: - What are the obstacles that you face on your site as a trainer and supervisor to the efficient handling of site $\mathrm{H} \& \mathrm{~S}$ induction training?

Literal replies comprised:

Subcontractor's workforce is problematic; they do not appear in weekly toolbox talks and site H\&S induction training. In the construction industry, it is very common that the workforce changes constantly. Mostly the workforce is uneducated and illiterate. There is a deprived $H \& S$ culture, and also the availability of funds for H\&S training is very rare.

Supervisors' responses to the intended queries implied administrative delinquency rather than considering it as a specific supervisor problem. The aptitude for organiz- 
ing H\&S induction appeared to be associated with administration problems but not only the supervisors.

\section{DISCUSSION}

Culture development and competency training are termed vital components (Teo and Ling 2009, Musonda and Haupt 2011). One of the accomplishments that made the construction site securer is training and education, as discovered by Dingsdag, Biggs et al. (2008). Site supervisors who are accountable for steering H\&S induction training to both old and new site employees, if not trained properly regarding $\mathrm{H} \& \mathrm{~S}$, will lack the capabilities and aptitude to handle site H\&S inductions. The study focused on the construction industry of Pakistan, a developing country where lack of resources makes the scenario even worse. The H\&S training among site supervisors was insufficient, as illustrated by the results of interviews and surveys steered as part of this research. It seems that most of the construction firms have prioritized the implementation of works as contrasting to fields, for instance, H\&S training. Lutchman, Maharaj et al. (2012) apprehended this interpretation; the authors determined from their research that in emerging nations such as Pakistan, organizational and financial resources are inadequate in medium and small-sized companies for efficient site H\&S administration incorporating the training of supervisors to attain the necessary H\&S skills.

The lack of adequate management interest was found to be the major reason for the incompetency of supervisors. In altering the insecure conduct of employees, higher administration's liability to workplace H\&S training among the utmost significant variables (Naoum 2011). Allotting adequate resources for H\&S, obtaining contemporary technologies, for instance, audio/visual aids and translator equipment, besides commending training programs for supervisors and workforces, reveal the leading management's dedication to workplace H\&S training, for instance, weekly toolbox talks and site H\&S induction in an efficient manner as argued by Hughes and Ferrett (2012). For efficient H\&S supervision on any construction site, higher management's dedication to workers $\mathrm{H} \& \mathrm{~S}$ is exceedingly necessary. In advancing a suitable
H\&S culture, commitment is a vital aspect (Musonda and Haupt 2011). An investigation led by Okorie and Musonda (2020) in Nigeria also found that the supervisors were not competent and skilled enough to conduct site H\&S induction training to the site workforces. The primary reason found was inadequate H\&S training of supervisors, management's lack of interest, and lack of usage of current H\&S training equipment. These findings also resemble the outcomes of the present study, as the present study also found that the management's lack of interest is the primary reason for supervisors' inadequate H\&S competencies and skills.

The second most significant factor found responsible for inefficient site H\&S induction training by supervisors is the supervisors' lack of adequate communication skills. The efficiency of supervisors to handle site inductions is considerably influenced by the aptitude to communicate. Dingsdag, Biggs et al. (2008) established that communication as an action guaranteed a harmless construction site. But if the supervisors had not possessed the pertinent or present familiarity on H\&S, an efficient communication essential for supervisors to manage inductions cannot be conceivable. The extent of training that the supervisors have accounts for the proficiency to interconnect. Correspondingly, the competency to communicate is also uttered by the tools that the supervisors have at their disposal.

If the information is obtained and inferred as planned by the transmitter, it shows that communication is effective. Effective communication can be made possible by utilizing current technology, such as translation equipment and audio/visual aids. Conferring to Bust, Gibb et al. (2008), approaches like this can enhance interaction and perceptiveness regarding H\&S among construction employees. In Southern Florida, the Hispanic migrant site workforces experienced an elevated accident rate due to not utilizing contemporary technologies, for instance, translation equipment and audio/visual aids, as found by Vazquez and Stalnaker (2004). The level of communication between the workforce and supervisors can be improved due to modern equipment. Similarly, the construction sites involving Language interpreters and His-

Table 3: Factors affecting for efficient handling of site H\&S induction training by supervisors

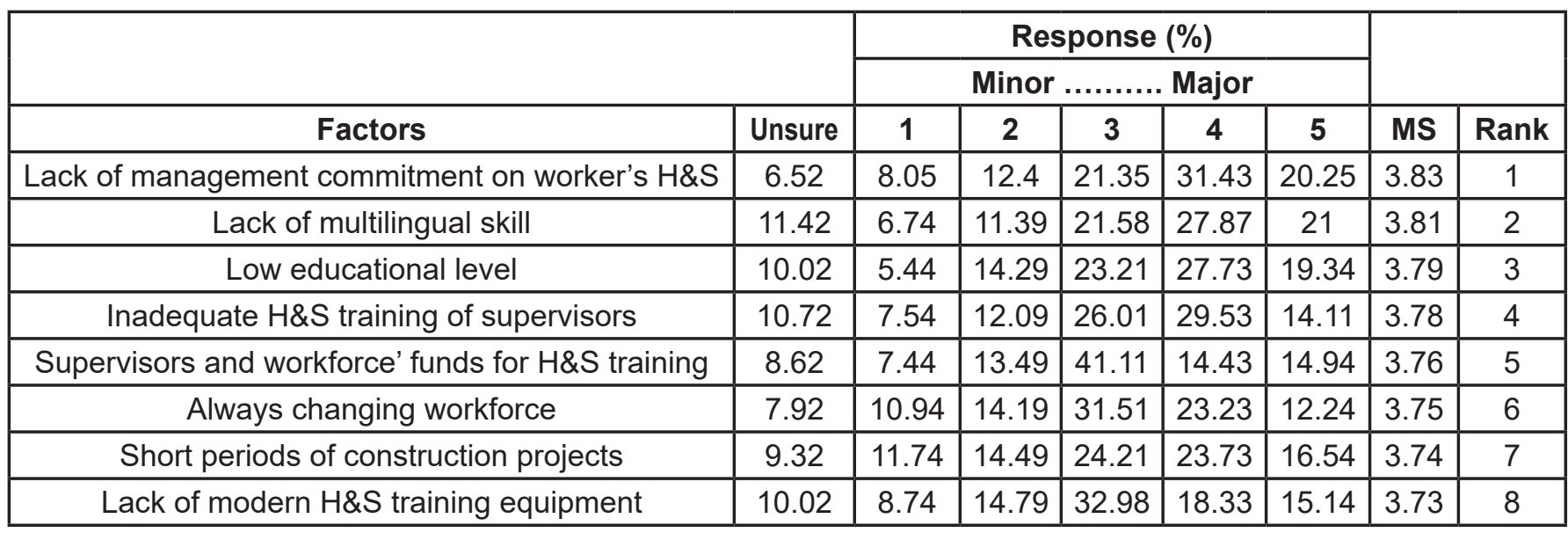


panic migrant workforces achieved a low accident rate, as discovered by Vazquez and Stalnaker (2004).

The level of education of supervisors and workers plays a vital role in the effective and efficient progression of site tasks. The level of management failure in small-sized construction firms in training and teaching supervisors on the usage of contemporary technologies that encourage a learning and teaching atmosphere among a substantial section of inexpert construction workforces was found to be alarming, as specified by the remarks made by the supervisors. In most of the emerging nations, the contemporary H\&S teaching aids are deficient, so as in Pakistan. Where they are present, supervisors were incompetent and were not skillful enough to manage them, as Lutchman, Maharaj et al. (2012) witnessed. Likewise, the H\&S performance was negatively impacted by the deficiency of competencies and skills among site supervisors and the H\&S induction training to site workforces, as indicated by Hinze (2006). This suggests that the higher competency levels of supervisors and workers are essential for the effective use of technology.

Yet, its management's commitment that is responsible for adopting modern technology, H\&S training, the usage of translation equipment, and audio/visual aids. The management's commitment from the conclusions of this investigation was found to be minimal, and the extent of $\mathrm{H} \& \mathrm{~S}$ training and education was correspondingly negligible. Validated concerning the training of the ILO (2005), and Goetsch (2012), who observed that the absence of dedication of the management was evident in fields, for instance, monetary facility for H\&S education and training, predominantly in evolving nations, and this had an adverse impression on the site H\&S functioning, the findings of this research suggest a low level of training. To conduct H\&S induction, a critical element confirming that supervisors accomplish the mandatory abilities is management dedication.

In Pakistan, the main reason for the poor H\&S training structure is the inadequate availability and implementation of legislation and insufficient regulation nature of the concerned authorities. The Factories Act 1934 is the prevailing law in Pakistan regulating occupational health and safety. It marks its roots in legislation got from the Indian subcontinent at the time of independence of $\mathrm{Pa}$ kistan. The existing law specifies safety provisions for workers hired by the factories. Regrettably, the construction industry in Pakistan is deprived of any specific occupational health and safety laws until now. A significant number of accidents happening at construction sites remain unreported to the concerned authorities because of the lack of enforcement of labor laws. For the construction industry of Pakistan, the formulation, introduction, documentation, and enforcement of safety rules and regulations is of paramount necessity. The need for an administrative body for the implantation of these rules and regulations is also inevitable.

\section{CONCLUSIONS}

The research aimed to ascertain the level to which the training on H\&S is provided to the supervisors in the construction industry; to what efficiency the supervisors were capable of managing a site H\&S induction and the supervisor's ability to handle H\&S induction is affected by what factors. The outcomes reveal that the construction corporations in Pakistan, specifically medium and small administrations, had little or no training in H\&S and, consequently, led to questions on the supervisor's H\&S abilities and skill to supervise H\&S induction training to site workforces in Pakistan efficiently. The results specify that supervisors lack the required H\&S skills and competencies, and mostly these supervisors are from small-sized construction firms. Results also proposed that in a maximum of the construction corporations, mainly the small-sized corporations, the senior management is unsuccessful in fulfilling their accountabilities. To apportion funds for H\&S and endorse training for supervisors is the administration's obligation as specified in the literature. For supervisors, if the higher management fails to support H\&S training, it might interpose to the supervisor's deficiency of aptitudes and incompetency for the efficient control of H\&S induction training to site workforces. Moreover, the absence of consciousness or ability to utilize audio/visual and translation apparatus, a considerable number of amateurish workers, and the nonexistence of administration devotion was ascertained as one of the significant aspects that influenced the supervisor's capability to manage H\&S inductions and the capacity to manage efficient site H\&S induction was involving uncertainty owing to these factors.

\section{IMPLICATIONS AND RECOMMENDATIONS}

This study's outcomes portray that the organizations do not give any significance to the H\&S training capabilities of the supervisors. Thus, the concerning authorities must ensure that the organizations take responsibility and ensure that the supervisors are equipped with adequate skills. Given the outcomes, to dodge the delinquency of disappointment to accomplish H\&S development objectives, the research proposed few recommendations subsequently. The administration of construction corporations must establish the significance of the supervisor's H\&S training. Not only the site H\&S working is enhanced by the H\&S training and education of supervisors, but it also increases their H\&S competency. Regardless of their size, the construction firms, for efficient site H\&S training, must obtain and utilize current technologies, for instance, visual (audio) and translation equipment, especially in nations such as Pakistan, where a considerable fraction of the workforce is inexpert. Precisely, among medium and small-sized construction firms, an emphasis on enhancing communication among employees and supervisors as an approach to improve H\&S execution ought to be followed and exhilarated. Management commitment to H\&S plans must be supported and stressed, particularly in enhancing supervisors' communication 
and capability. The overview of the fallouts may be restricted owing to the sample size of the interviewees and the extent of the investigation. Yet, results of the present research exhibit that it would be irrational to follow H\&S culture deprived of careful deliberation of the part played by the construction supervisors, particularly in medium and small-sized construction corporations in Pakistan and other emerging nations.

\section{AVAILABILITY OF DATA AND MATERIALS}

The data that support the findings of this study cannot be provided due to personal reasons.

\section{COMPETING INTERESTS}

The authors declare that they have no competing interests.

\section{FUNDING}

No funding is involved in this research.

\section{AUTHORS' CONTRIBUTIONS}

All authors have contributed to the scientific work and therefore share collective responsibility and accountability for the results. All authors read and approved the final manuscript.

\section{ACKNOWLEDGMENTS}

The authors would like to thank anonymous reviewers for their valuable comments.

\section{REFERENCES}

1. Abdelhamid, T. S. and J. G. Everett (2000). "Identifying root causes of construction accidents." Journal of Construction Engineering and Management 126(1): 52-60.

2. Amiri, M., et al. (2017). "Fuzzy probabilistic expert system for occupational hazard assessment in construction." Safety Science 93: 16-28.

3. Brauer, R. L. (2006). Safety and health for engineers, Published by John Wiley \& Sons, Inc. Hoboken, New Jersey.

4. Bust, P. D., et al. (2008). "Managing construction health and safety: Migrant workers and communicating safety messages." Safety Science 46(4): 585602.

5. Chan, A. P., et al. (2016). "Strategies for improving safety and health of ethnic minority construction workers." Journal of Construction Engineering and Management 142(9): 05016007.

6. Chan, A. P., et al. (2017). "Construction safety and health problems of ethnic minority workers in Hong Kong." Engineering, Construction and Architectural Management.
7. Choudhry, R. M., et al. (2008). "Challenging and enforcing safety management in developing countries: A strategy." International Journal of Construction Management 8(1): 87-101.

8. Dingsdag, D. P., et al. (2008). "Understanding and defining $\mathrm{OH} \& \mathrm{~S}$ competency for construction site positions: Worker perceptions." Safety Science 46(4): 619-633.

9. Farooqui, R. and S. Ahmed (2008). "Assessment of Pakistani construction industry-current performance and the way forward." Journal for the Advancement of Performance Information \& Value 1(1).

10. Fewings, P. (2010). Chapter 14 Working at height and roofwork. ICE manual of health and safety in construction, Thomas Telford Ltd: 167-179.

11. Flick, U. (2014). An Introduction to Qualitative Research, SAGE.

12. Goetsch, D. L. (2012). Construction Safety \& Health, Pearson Higher Ed.

13. Hughes, P. and E. Ferrett (2012). Introduction to health and safety in construction, Routledge.

14. Health and safety Executive (HSE). (2010). Reducing error and influencing behavior - HSG-48. Bootle: Health and safety Executive.

15. Hinze JW. (2006). Construction safety, Published by Prentice Hall, New Jersey.

16. International Labor Organization (ILO). (2010). ILO standard on occupational safety health: promoting safe and healthy working environment, Geneva.

17. Imriyas, K., et al. (2007). "A framework for computing workers' compensation insurance premiums in construction." Construction Management and Economics 25(6): 563-584.

18. International Labor Organization (ILO). (2005). Safety and health in construction, Geneva.

19. Khan, M. W., et al. (2019). "Occupational health and safety in construction industry in Pakistan using modified-SIRA method." Safety Science 118: 109118.

20. Kheni, N. A. (2008). Impact of health and safety management on safety performance of small and medium-sized construction businesses in Ghana, Loughborough University.

21. Le, Y., et al. (2014). "Overview of corruption research in construction." Journal of management in engineering 30(4): 02514001.

22. Leedy, P. D. and J. E. Ormrod (2010). "Practical Research."

23. Lingard, H. and S. M. Rowlinson (2005). Occupational health and safety in construction project management, Taylor \& Francis. 
24. Lutchman, C., et al. (2012). Safety management: A comprehensive approach to developing a sustainable system, CRC press.

25. Memon, A. H., et al. (2017). "Factors causing health and safety hazards in construction projects in Pakistan." Mehran University Research Journal of Engineering and Technology 36(3): 559-568.

26. Musonda, I. and T. C. Haupt (2011). Identifying factors of health and safety (H\&S) culture for the construction industry. THE SIXTH BUILT ENVIRONMENT CONFERENCE JOHANNESBURG SOUTH AFRICA 31 JULY-2 AUGUST 2011.

27. Musonda, I., et al. (2012). "Assuring health and safety performance on construction projects: Clients' role and influence." Acta Structilia 19(1): 71-105.

28. Naoum, S. (2011). "People and Organizational Management in Construction."

29. Okorie, V. and I. Musonda (2020). "An investigation on supervisor's ability and competency to conduct construction site health and safety induction training in Nigeria." International Journal of Construction Management 20(5): 357-366.
30. Okorie, V. and J. Smallwood (2012). The impact of poor communication skills on construction site health and safety performance in South Africa. Proceedings: CIB W099 International Conference on Modelling and Building Health and Safety.

31. Spangenberg, S. (2009). "An injury risk model for large construction projects." Risk Management 11(2): 111-134.

32. Sunindijo, Y. and P. X. Zou (2012). "The influence of project personnel's emotional intelligence, interpersonal skill, and transformational leadership on construction safety climate development." International journal of project organization and management 5(1): 1-13.

33. Teo, E. A. L. and F. Y. Y. Ling (2009). "Enhancing worksite safety: Impact of personnel characteristics and incentives on safety performance." International Journal of Construction Management 9(2): 103-118.

34. Vazquez, R. F. and C. K. Stalnaker (2004). "Latino workers in the construction industry." Professional Safety 49(6): 24. 